\title{
Cognitive-Behavioral Therapy for Envy
}

\author{
Robert L. Leahy ${ }^{1} \mathbb{D}$
}

Published online: 29 July 2020

(c) The Author(s) 2020

\begin{abstract}
Envy is a ubiquitous social emotion often associated with depression, hostility and shame. Often confused with jealousy which involves the fear or anger that a primary relationship is threatened by a third party, envy is an emotion focused on threats to status such that another person's "gain" is viewed as a "loss" for the self. There is very little in the cognitive behavioral literature on the nature and treatment of envy. In this article I outline the research on the nature of envy, the evolutionary model of envy, the relevance of an integrative CBT model that draws on Beck's Generic Cognitive Model and Emotional Schema Therapy, and the implications for case conceptualization and treatment.
\end{abstract}

Keywords Beck $\cdot$ Cognitive therapy $\cdot$ Envy $\cdot$ Anxiety $\cdot$ Depression $\cdot$ Emotional schema therapy $\cdot$ Case conceptualization

\section{Introduction}

As the pundit Alice Roosevelt Longworth commented, "If you haven't got anything nice to say about anybody, come sit next to me." Envy and its cousin Schadenfreude are emotions and thoughts that many of us can recognize, but about which we may feel both shame and guilt. How can you wish ill of someone who has success? The answer may be, "Because we are human". Envy is a social emotion focused on problematic comparisons with others where the self is viewed as performing poorly compared to a specific individual. We can see envy in a wide range of social contexts-envy between professional colleagues, siblings, and friends. Although envy and jealousy are often confused, envy is best described as competition within a hierarchy perceived by the individual as important, whereas jealousy is always about three people-that is, jealousy involves the perception that a valued relationship is threatened by a third party. Further, it is possible to feel envious of someone who activates one's jealousy. For example, a man might be envious of another man who is more successful and whose success is perceived as an attractive temptation to his partner.

Emotion theorists have proposed that there are primary or basic emotions-for example, Ekman $(1992,2003)$ posited

Robert L. Leahy

rleahyaict@gmail.com

1 American Institute for Cognitive Therapy, 136 East 57th Street, Suite 1101, New York City, NY 10022, USA six basic emotions (fear, anger, joy, sadness, disgust, and surprise) while Plutchik (2001) posited eight primary emotions (anger, fear, sadness, disgust, surprise, anticipation, trust, and joy). Other emotions - "secondary emotions"are presumed to be derived from these primary emotions. We can view envy as a secondary, "superordinate" or complex emotion that can be manifested in a wide range of other emotions, such as shame, guilt, resentment, anxiety, sadness, anxiety, and anger. Envy is not "reducible" to these other emotions, but rather is manifested in different ways by individuals. For example, an individual can feel envious, but not feel shame or anger over their envy, although many other envious people will feel these other emotions. Envy can take various forms and the individual can evaluate their envy in a number of ways.

Ekman $(1992,2003)$ does describe envy and jealousy as universal emotions but suggests that there are no universal facial expressions that reflect these emotions. Other emotion theorists emphasize cognitive aspects of emotion, such as Frijda (1988) who views emotions in terms of goals and action tendencies, Oatley and Johnson-Laird (1987) who view emotions as coordinating actions and plans, and Izard (2009) who specifically mentions emotional schemas, but uses this term to refer to how these more complex emotions are compounded out of basic emotions and often involve complex appraisals. Other emotion theorists have proposed a constructivist model of emotion such that the individual "conceptualizes" their affective state as a specific emotion (Lindquist and Barrett 2008; Barrett et al. 2007) based on the 
context and expectations that they bring to the experience. The current emotional schema model is not inconsistent with the constructivist model advanced by Barrett et al. Rather, the emphasis in the proposed emotional schema model is on the evaluations, explanations, and strategies that are used once an emotion arises (Leahy 2015).

Envy is related to social comparison processes which Festinger (1954) described as a universal motive (1954). Social comparisons (e.g. "How am I doing compared to others on this task?") are presumed to underlie information about how to succeed, a proxy for self-esteem, and as providing motivational information. Envy is a status anxiety emotion that draws on a near universal positive evaluation of the importance of status across age groups, gender, social classes, and cultures with individuals at higher status enjoying greater physical and emotional health, higher self-esteem and subjective well-being (Anderson et al. 2015). (See Lindholm (2008) for a discussion of cultural differences in envy). Individuals are more likely to experience envy when the target behavior is valued by them, they believe it is possible that they might achieve these goals, they view the target of envy as "undeserving", and they value status and recognition (Van Dijk et al. 2006; Cohen-Charash and Mueller 2007). For example, a person is not likely to be envious of an Olympic athlete in gymnastics if they do not think it is relevant to their goals of being a successful academic psychologist. It is also less likely that one will be envious if they view themselves as lacking any skill in gymnastics. Envy is magnified if the target of envy is viewed as achieving their status through cheating or unfair advantage, such as nepotism. Finally, those individuals who place considerable value on approval or status are more likely to experience envy, viewing the achievements of others as reflecting negatively on one's own status (Fiske 2011). Envy can lead to taking pleasure in the misfortune of someone who is competing in a realm of behavior relevant to self-evaluation (Schadenfreude), with people exhibiting more envy and schadenfreude about people of similar gender and comparison level (Van Dijk et al. 2006). Envy also has implications for cognitive processing with individuals whose envy has been primed attending to and recalling more information about the individuals who are envied (Hill et al. 2011).

Envy is associated with depression, anger, anxiety, rumination, and interpersonal hostility (Appel et al. 2016). Research on envy has identified three styles of emotional response-hostile (malicious), depressive and benign envy. In each case the "envious" person has an emotional response to the perceived status of another person, with "benign envy" reflecting an adaptive response, including the ability to learn from and emulate the envied person (Parrott 1991; Van den Ven et al 2011). Dryden (2003) describes how envy can be both destructive and motivating, depending on how the individual responds to their emotion. This is consistent with the current formulation. One might reasonably argue that this is not how people think about envy, but it does suggest that whatever discomfort one might feel toward the envied person could serve an adaptive function by leading to emulation or motivation to work harder.

Hostile envy is reflected in the experience of Schadenfreude where the individual takes pleasure in hearing of the problems of the target of envy. For example, an academic colleague may take pleasure in hearing that a competitor in their field has had their work strongly criticized. Another form of hostile envy is seen in the hostile, belittling comments that are directed toward the target of envy, often suggesting that the individual did not deserve the recognition that they gained. Depressive envy involves feelings of inferiority, defeat, humiliation, and helplessness when comparing oneself with the envied person. In some cases, the individual may withdraw entirely from the "field of competition"-giving up the pursuits of goals that are related to the envy. Depressive envy can also be seen in withdrawal and disengagement from the envied person, thereby reducing the opportunity for "reminders" of one's "defeat" and "inferiority". Depression is often associated with envy, as evidenced in the relationship between envious observations on Facebook with depression and low self-esteem (Appel et al. 2016). Benign envy entails positive admiration of the envied person, often with the recognition that the other person justly deserved their status (Van den Ven et al. 2015). Lange and Crusius (2015) developed a brief scale that assesses malicious and benign envy-the Benign and Malicious Envy Scale (BeMaS). Examples of items that tap into Malicious Envy include "I wish that superior people lose their advantage" and "If other people have something that I want for myself, I wish to take it away from them." Examples of Benign Envy include the following items: "Envying others motivates me to accomplish my goals" and "I strive to reach other people's superior achievements". Lange and Crusius (2015) found that Dispositional Benign Envy was related to Hope for Success (an aspirational motive) while Malicious Envy was related to Fear of Failure (an avoidant motive). There are no specific cutoff points on this scale defining thresholds, but scores on these subscales are related to other variables. The clinician and client can evaluate whether the envy is "functional" (for example, motivating) or "unhelpful" (for example, leading to rumination, hopelessness, and humiliation).

Benign envy is associated with the view that positive outcomes for the other were deserved and controllable whereas malicious envy was more often expressed when positive outcomes were viewed as undeserved (van de Ven et al. 2012). Envy can motivate one to try harder to move up in the status hierarchy (van de Ven et al. 2009). Malicious envy (angry and hostile feelings toward an individual performing better than the self) led to decrements of performance (van de 
Ven et al. 2011). Envy up is associated with anger, shame, humiliation, lowered self-esteem and a sense of unfairness, whereas "scorn down"-which is often associated with contempt-focuses more on the self and decreases the ability to understand or have empathy for those of lower status (Fiske 2010).

\section{An Integrative Cognitive Behavioral Model of Envy}

I review the evolutionary adaptive value of envy (dominance hierarchies, social rank theory), the fundamental concern for fairness, schemas related to status, maladaptive "coping" (undermining the "competition" and avoidance of competitors), rumination, complaining, and self-critical thinking. The integrative clinical model includes the following: normalizing envy, validating envy to decrease shame and guilt, relating envy to positive values, focusing on turning envy into admiration and emulation, differentiating the selfconcept beyond a focus on one dimension, and acceptance of envy while acting on valued goals. In addition, we will examine how we can modify dysfunctional beliefs about social comparison: Labeling ("He's a winner, I am a loser"); Fortune-telling ("She will continue to advance, I will fall behind"); Dichotomous thinking ("You either win or lose"); Discounting positives ("The only thing that counts is getting ahead"); and Catastrophizing ("It's awful not to be ahead of others"). Finally, we will review a case conceptualization of a case of depressive and anxious envy.

The Evolutionary Model of envy suggests that members of groups compete for higher status and dominance. Higher status is associated with greater access to food, mates, procreative success, nesting sites, less depression, less anxiety, better health, better life prospects, lower cortisol, and longevity and status often can be passed down across generations (Sapolsky 2004, 2005). Based on the assumption that ancestral humans competed for limited resources, competitive motivation for higher status can be seen as a universal motive. Moreover, in order to reduce unnecessary and failed attempts to challenge status, individuals utilize behavioral gestures that communicate higher or lower status-that is, status signaling (Mazur 1985). Further, the Social Rank model of depression proposes that withdrawal, avoidance and subservience serve the function of reducing pointless challenges to higher status, thereby preserving some survival value for those at lower status (Gilbert and Allen 1998). Thus, one response to defeat or loss of status can be depressive subservience and avoidance. Envy may have much in common with anger as a "negotiating strategy" (for example, Sell et al. (2009) "recalibration of anger model"). However, envy does not always involve anger and may be directed toward individuals with whom the person has no contact and, therefore, no position to negotiate. However, it is plausible that envy and concomitant anger in some contexts may help negotiate more desired distribution of resources and power.

An opposing system in groups argues for the value of altruism and fairness such that hoarding of resources to the disadvantage of other group members will lead to alliances forming to challenge the dominant figures. This "fairness" and emphasis on "sharing" resources suggests that group members might confer higher status on individuals who show generosity - a kind of "distributive justice" motive. Evidence of preferences for fair distributions or "deservingness" of rewards can be seen in animals and humans (Anderson et al. 2017; Brosnan and de Waal 2014). Concepts of fairness or distributive justice appear to prevail over absolute level of consequences (Hill and Buss 2006, 2008). Thus, envy may be viewed as reflecting two motivational systems-pursuit of dominance and emphasis on fairness.

\section{Envy Mode}

The Emotional Schema Therapy Model (EST) is similar to Beck's generic cognitive model (Beck and Haigh 2014) in proposing that emotions comprise synthesized "modes" that systematically integrate thoughts, assumptions, schemas, behavioral tendencies, interpersonal strategies and emotional regulation strategies (Leahy 2015). Additionally, the EST model proposes that implicit theories about envy include beliefs about the legitimacy, normalcy, pervasiveness, shamefulness, duration, control, and acceptability of envy. This integrative CBT model proposes that the Envy Mode can be viewed from an evolutionary, socialization, cultural and cognitive perspective. The evolutionary processes include competition within dominance hierarchies, attempts to displace others viewed as having higher status, and the advantages in terms of procreation, survival and access to resources conferred on those of higher status, and standards of fairness and just distribution. Cultural factors contribute to the vulnerability to envy, with some cultures placing more emphasis on status, the ability to achieve higher status, the legitimacy of status, and the specific content that reflects status (Schoeck 1969; Quintanilla and de Lopez 2013). Cultural factors include emphasis on specific standards and content of evaluation, such as materialism and appearance, positive views of fairness, challenges to the legitimacy of status, and perceived status within valued reference groups. Socialization factors that give rise to envy include emphasis on doing better, linking praise from others with achievement or admired qualities (such as beauty, physical prowess), conditional love, humiliation, and perfectionistic standards ("never being good enough"). In addition, it may be that envy is more commonly found in individuals 
who are competitive, engage in excessive social comparison, or endorse narcissistic beliefs of uniqueness and superiority. Each of these contribute to envy and are thereby reflected in the cognitive system of automatic thoughts, maladaptive assumptions, and personal and interpersonal schemas.

The Standard Cognitive Model advanced by Beck suggests that envy, like many other emotions, reflects levels of cognitive processing and biases that lead to vulnerability and persistence of envy. These include negative automatic thoughts, maladaptive assumptions or rules, and personal and interpersonal schemas. Examples of personal schemas related to envy are the following: Special Person ("I need to be viewed as special, superior, and admired by others"), Defective ("Their success proves how inferior I am"), Incompetent ("They can do anything that they want to do but I cannot do anything. I am weak and unable to take care of myself"), and Conscientious/ Responsible ("I work so hard, but they get the rewards. I am either lazy or this isn't fair"). The cognitive content of envy and alternative challenges or responses are shown in Tables 1, 2, 3, 4 for these different levels of thinking and responding to one's envy.

\section{The Emotional Schema Model of Envy}

The Emotional Schema Model draws on the generic cognitive model, but also recognizes the cultural and socialization factors that contribute to beliefs about emotions and strategies of adaptation and communication of those emotions. In this section we will review the assumptions underlying the idealization of status, the tendency to focus on status to exclusion of other sources of emotional enrichment, beliefs about the emotional experience of envy, and problematic coping strategies. Finally, we will examine a case conceptualization of envy that can inform an integrative cognitive behavioral approach.

\section{Idealizing Status}

Just as the envious person may derogate their own success or life experiences, envy is often associated with idealizing the presumed lives of people who have obtained some status. We see this in the admiration and idealization that people often confer on celebrities or people with wealth, although we seldom have access to the real-life experiences of these people. This reinforces the maladaptive assumption, "The way to be happier in life is to gain status". The idealization of the lives of others is usually based on fantasy rather than facts. Do we really know how celebrities or other "successful" people experience their daily lives? Are we able to determine how their "status" in one domain translates to fulfillment and satisfaction in other areas such as personal relationships, family life, health, or personal happiness? Perhaps, because of the tendency to idealize celebrities it is easy to see how this "envy" of those with higher status gives rise to an interest in learning about their problems and personal tragedies. Schadenfreude is usually focused on those with higher status. We love to hear about people falling from the heights, especially if they crash and burn.

\section{Deconstructing Status}

An alternative to this view is to "deconstruct" status. We can think of "status" as reflecting different perceived domains of value. For example, there may be people who may be viewed as having status in the arts, law, academics, or sports. However, within each of these domains there are segments of the hierarchy that may strongly disagree about the status of an individual. For example, in academics within the field of psychology individuals in neuroscience may view achievements in social psychology as having less value, whereas people in social psychology might view achievements in neuroscience as not relevant to valued concerns in their own field. Moreover, since status domains are "local"-we only know what we know- we may have no idea what the other person's work is or how to evaluate it. Thus, status is always "local", "arbitrary" and dependent on the views of others. All of these factors are either transitory or unknowable-that is, status is often a temporary "position" in a local hierarchy and, in fact, one can never be quite sure about how one is viewed by others. The status of someone in one career may not be viewed as of no status by someone who is not in that same career path. Moreover, we can never be quite sure how others are evaluating our status. The foregoing model of deconstructing status may be incorporated as a model of clinical intervention for the envious individual. Too often "status" is a concept that may go under-examined, leaving the patient with the belief that it is essential to one's well-being.

\section{Range of Valued Action}

Just as the envious person idealizes the target of envy and may over-value the benefits of status, they also ignore or discount the range of valued action available to them. It is as if one's meaning in life is reduced to a level of success on one dimension. An alternative to this myopic vision is to expand awareness of other valued goals. Two techniques are helpful. First, the client is asked to consider all the things that they can still do even if they do not have this higher status. For example, a business executive who had become focused on his lower status compared to someone promoted above him, was able to list a wide range of behaviors that he could still pursue - in fact, everything that he had always been able to do. When asked to list what he was no longer able to do because someone had higher status, he could not identify a 


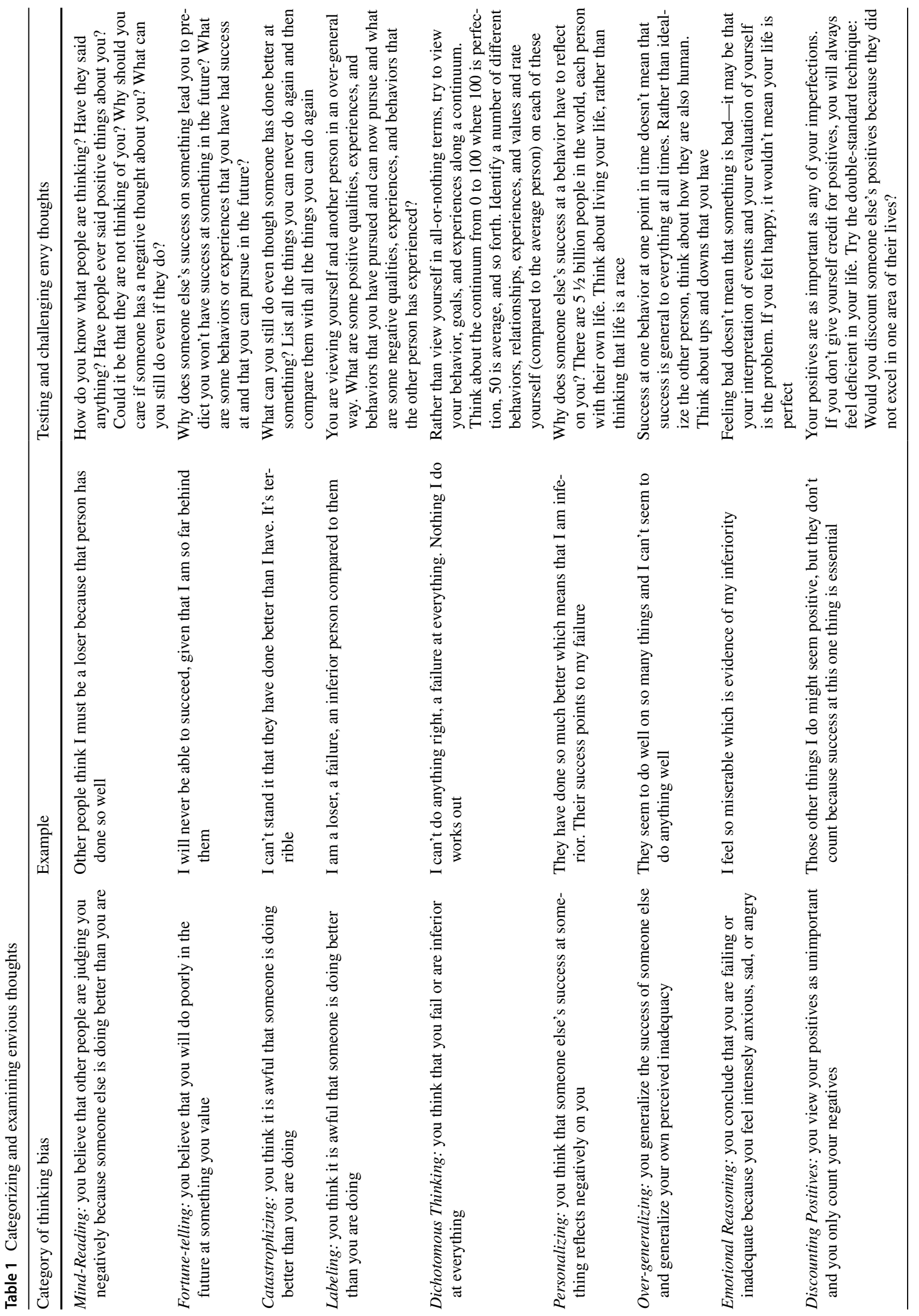


single behavior. Secondly, the therapist introduced the idea of a Life Portfolio. With this technique a "Life-Space Pie" is represented by a circle with ten "pieces". The client is asked to identify what other things in their life have meaning and to label those pieces of their life portfolio. Then, they are asked what per cent of their focus they wish to give to each of these pieces. This technique assists in detaching from a single focus on arbitrary status to an awareness of other valued action. In some case, this assists in redirecting the individual to areas of their lives that have gone ignored. In the case of the business executive it led to his awareness that he was not giving enough attention to his son and to his wife.

\section{Emotional Schema Beliefs and Envy}

Cognitive factors not only give rise to the emotion of envy, but they are also implicated in the individual's interpretations, tolerance, and strategies for coping with envy. The Emotional Schema Model proposes that a variety of beliefs can add to the difficulty in coping with envy. These include beliefs that "My envy goes on and on" (Duration), "I can't control my envy" (Controllability), "I shouldn't feel this way" (Shame/Guilt), "Other people don't feel this way" (Lack of consensus), "My envy doesn't make sense" (Incomprehensible), "I am an envious person" (Labeling Self as Emotion), "I can't accept the fact that I feel envious"( Low acceptance), "I can never tell anyone about this" (Low expression), "No one could validate or understand the way I feel" (Low validation), "How can I feel envious when I also like this person?" (inability to accept ambivalence), "It's irrational, so I shouldn't feel this way" (Overemphasis on rationality) and "I am an envious person" (Identifying self with the emotion).

Accordingly, the EST model attempts to reverse many of these negative interpretations of the emotion of envy. These responses are shown in Table 3 ("Beliefs About the Emotion of Envy and Adaptive Alternative Beliefs") and Table 4 ("Maladaptive Strategies and Alternative Perspectives").

\section{Case Conceptualization}

The integrative CBT model can provide the clinician with a framework for conceptualizing an individual case of envy. (See Fig. 1 for a Generic Case Conceptualization of envy.) For example, the client was a married man with children who has been passed over for a promotion. His envy was focused on a colleague who was promoted ahead of him. Although the colleague was someone he viewed as competent, he also viewed himself as competent and deserving of promotion. The therapist provided an overview of envy based on the ideas outlined in this article. Although his primary presenting complaint was 
Table 2 Maladaptive assumptions and adaptive alternative

Assumption/rule
If you don't succeed at the top, then you have failed
I should do better than others
My value as a person depends on my status
If you are not very successful, people will think less of you
I need to impress others with my success and status
People are either successes or failures

I can't accept any unfairness

I should undermine the success of others who I envy

If they succeed, it means that I have failed

I should judge myself by how well I am doing in my achievements

There are winners and losers

Life is a race

Their success shows that I am falling behind

I can't stand it that they succeed
Challenges

This is all-or-nothing thinking and ignores the fact that life is a matter of degrees and that people have various degrees of success on a variety of tasks, not just one

Why should you do better? Why can't you accept who you are with human limitations and a range of possibilities. If you think that you should do better-or be the best-would you apply this demand on others? Why not give yourself credit for the things that you do?

Would you apply this to other people? Are there people of higher status who do unethical things? How does status lead to value as a person? What is value as a person?

Some people might, but why should you care? Maybe people are not thinking of you that way-or at all at this moment

Why? Why not try to be a good friend, a good listener, act according to your positive values

How could this be if everyone fails at something and succeeds at other things? What is the consequence of dividing people up into success and failure? Why not treat people with compassion and acceptance?

Unfairness is part of life and not accepting it will only make you miserable. It might make sense to challenge unfairness or seek justice, but accepting that unfairness exists is part of living in the real world

How will this help you? Focusing on negative goals and retaliation will lead others not to trust you. Focus on your own goals and values rather than tearing others down

If they succeeded at something that means that they achieved something in the moment. If someone achieves something it doesn't make sense to me to conclude that you can't achieve something, too. Rewarding behaviors are not scarce

Why do you have to judge yourself at all? Why not live your life and make it meaningful and joyful? In fact, if you judge anything, judge whether you treat people decently_including yourself. Rather than judge, show compassion. Begin with yourself

There are behaviors that pay off in the immediate situation and others that do not. There is no such thing as a person who is a "winner." Even people who "win" the Olympics, like Michael Phelps, can get depressed

Life involves meaning, relationships, fun, work. It's the meaning that you give to each of these things that matters

Why does life have to be a race with people falling behind? Why not look at your life as your path, your interests, your values?

Think of all the things you can still do even if they succeeded. How are you really any worse off if they have some success? depression and rumination, the therapist identified his envy as a central vulnerability. The evolutionary model was explained, balancing the universal desire for higher status in a dominance hierarchy with a "fairness motive" that rewards should be equitable. In addition, the therapist normalized his envy, indicating that a universal emotion is not something that one should feel guilty or ashamed about. Moreover, the experience of being passed over, which gave rise to envy and a sense of defeat, was related to his early childhood experience of feeling humiliated and left out of groups of other children, which was now interpreted as based on the fact that the other children thought he was smarter and, ironically, because of their hostile envy, excluded him from the group. His core schema was that he was not good enough to be included and his schema about others was that they were rejecting.

Rather than reduce his identity to "I am an envious person", we differentiated his self-concept as one of many emotions, thoughts, achievements, values and possible action. We identified several of his maladaptive strategies including rumination, self-criticism, and avoidance and targeted each for treatment. Rumination was treated with meta-cognitive techniques (setting aside time for rumination, attentional training, detached mindfulness), selfcriticism was addressed with standard cognitive techniques (evidence for and against, double-standard, examining 
Table 3 Beliefs about the emotion of envy and adaptive alternative beliefs

\begin{tabular}{|c|c|}
\hline Emotional schema dimension & Rational and adaptive alternatives \\
\hline Duration & Your emotion of envy comes and goes. You have other emotions beside envy which also come and go \\
\hline Controllability & $\begin{array}{l}\text { You don't have to rid yourself of a feeling-just acknowledge it. In fact, when you shift your attention to other } \\
\text { things your envy decreases or is non-existent. This shift in focus and the change in envy indicate that you } \\
\text { have some control. Set aside "envy time", } 20 \text { min each day, and then focus on the envy. This will also show } \\
\text { some control }\end{array}$ \\
\hline Shame/guilt & $\begin{array}{l}\text { Having an emotion is not the same thing as acting in a malicious or unethical way. You didn't choose to have } \\
\text { this feeling. It is a universal experience }\end{array}$ \\
\hline Lack of consensus & Envy is universal—we see it in all cultures, in children and even in animals \\
\hline Incomprehensibility & $\begin{array}{l}\text { Your envy makes sense because you place emphasis on competition and status and you believe that another } \\
\text { person's success diminishes you }\end{array}$ \\
\hline Labeling self & $\begin{array}{l}\text { Your specific emotion is not the same thing as you as a person. You are far more complicated than that-you } \\
\text { have a wide range of feelings, not just envy, and they each come and go }\end{array}$ \\
\hline Low acceptance & $\begin{array}{l}\text { If you accept that you have envious feelings at times you will feel less ashamed and less controlled by them. } \\
\text { Accepting a feeling is the first step in coping with it. Make room for your envy }\end{array}$ \\
\hline Low expression & $\begin{array}{l}\text { You might want to be cautious about telling people about your envy, but listen to other people and notice how } \\
\text { much they envy. If you trust someone you might acknowledge that you sometimes feel envious. This might } \\
\text { help normalize your feelings so you don't feel alone }\end{array}$ \\
\hline Low validation & $\begin{array}{l}\text { You can begin by validating yourself-that your envy is a universal emotion, a difficult feeling, and one that } \\
\text { you can be supportive about- to yourself }\end{array}$ \\
\hline Intolerance of ambivalence & We often have mixed feelings about people-including those we feel envious about \\
\hline Over-emphasis on rationality & $\begin{array}{l}\text { It's not rational or reasonable to think you should be rational all the time. You are human, you are allowed to } \\
\text { have feelings }\end{array}$ \\
\hline Identifying self with the emotion & $\begin{array}{l}\text { You are not your emotion-your emotion is an experience that you have along with many other emotions, } \\
\text { thoughts and experiences }\end{array}$ \\
\hline
\end{tabular}

Table 4 Maladaptive strategies and alternative perspectives

\begin{tabular}{ll}
\hline Maladaptive strategies & Alternative beliefs \\
\hline Complaining & This may alienate other people and compromise your reputation \\
Derogating others & People may view this as being unfair and unsavory and may also negatively impact your reputation \\
Avoiding the target of envy & $\begin{array}{l}\text { This may deprive you of opportunities to benefit from working with or learning from others } \\
\text { Giving up }\end{array}$ \\
$\begin{array}{l}\text { If you give up you will lose any advantages of being a participant } \\
\text { Repetitive dwelling on this will only make you depressed. You can consider accepting things the way they are and } \\
\text { try to make the best of it }\end{array}$ \\
$\begin{array}{l}\text { Thiticizing yourself } \\
\text { envy? }\end{array}$
\end{tabular}

discounting the positives, over-generalizing and labeling), "unfairness" was treated with acceptance and commitment to positive goals such as forming alliances, obtaining feedback for how to improve his performance, using the target of envy as a role-model of success (turning envy into emulation), and developing a "business plan" for success by using problem solving, focus on positive goals, and managing upwards. Each of his emotional schema beliefs were examined and challenged including beliefs about duration (his envy was fluid and came and went during the day), controllability (he could both accept the envy for now but realize that his envy could be abated if he challenged his negative thoughts, accepted the situation for now, and focused on other goals. His shame about the emotion was addressed by normalizing envy, relating envy to evolutionary factors and socialization, and reframing envy as an emotion that could be turned into a positive (that is, emulation, motivation to improve, learning). Finally, he was able to step away from an over-focus on "status" within the system to develop a complex "Life Portfolio" of valued action including being a father, husband, son, member of a charitable organization, someone who was constantly learning, hobbies that he valued, and other valued action. 
Fig. 1 Cognitive behavioral therapy for envy

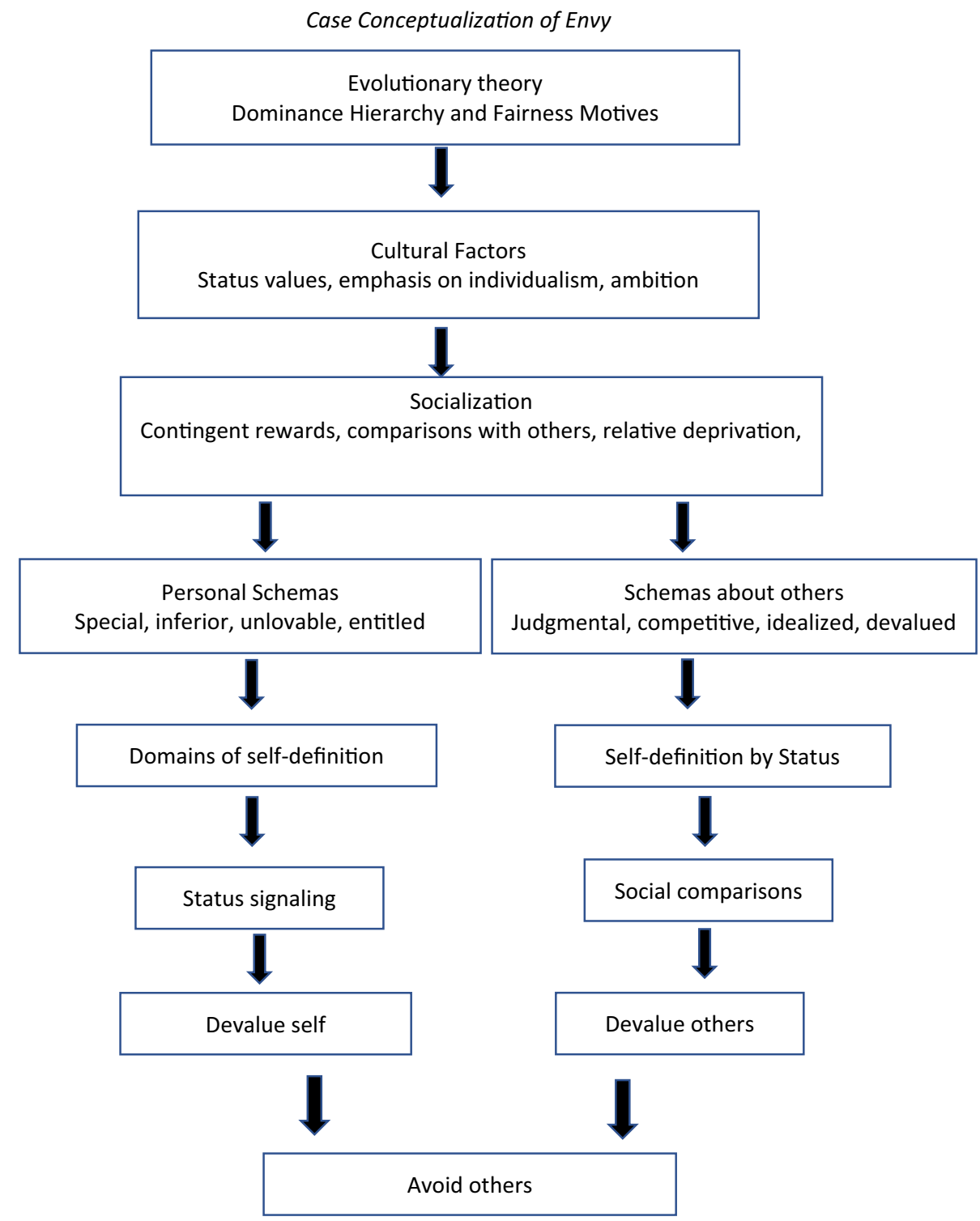

\section{Conclusions}

Despite the widespread experience of envy and its often debilitating depression, anxiety, hostility and ruminative qualities, this troubling emotion has gained little attention in the cognitive behavioral literature. In this article we have reviewed the factors that give rise to a range of envious responses-including depressive, hostile and benign envy- and have examined how envy is related to evolutionary factors that have been important for ancestral humans. These include the many advantages for survival and procreation conferred by higher status and, in conflict with dominance, the countervailing motives to seek fair distribution. Moreover, while recognizing the universality of envy, this emotion can be normalized, rather than reduced to a symptom of pathological narcissism.
An integrative cognitive behavioral model provides the clinician with a systematic roadmap for case conceptualization and strategic interventions. This includes assisting clients in recognizing the sources of envy that are beyond one's control including evolutionary, cultural and socialization factors, the advantage in accepting the experience of envy rather than attempt to suppress it or feel ashamed about it, a method to develop a plan to turn envy into admiration and even into emulation, strategies to reduce avoidance, sabotaging others, or giving up, techniques to address the ruminative aspects of envy, methods to identify and modify automatic thoughts, maladaptive assumptions and personal and interpersonal schemas, and techniques to examine and address unhelpful beliefs about the emotion of envy. 


\section{Compliance with Ethical Standards}

Conflicts of Interests The author declares that they have no conflict of interests.

Animal Rights No animal studies were carried out by the authors for this article.

Open Access This article is licensed under a Creative Commons Attribution 4.0 International License, which permits use, sharing, adaptation, distribution and reproduction in any medium or format, as long as you give appropriate credit to the original author(s) and the source, provide a link to the Creative Commons licence, and indicate if changes were made. The images or other third party material in this article are included in the article's Creative Commons licence, unless indicated otherwise in a credit line to the material. If material is not included in the article's Creative Commons licence and your intended use is not permitted by statutory regulation or exceeds the permitted use, you will need to obtain permission directly from the copyright holder. To view a copy of this licence, visit http://creativecommons.org/licenses/by/4.0/.

\section{References}

Anderson, C., Hildreth, J. A. D., \& Howland, L. (2015). Is the desire for status a fundamental human motive? A review of the empirical literature. Psychological Bulletin, 141(3), 574.

Anderson, J. R., Bucher, B., Chijiiwa, H., Kuroshima, H., Takimoto, A., \& Fujita, K. (2017). Third party social evaluations of humans by monkeys and dogs. Neuroscience \& Biobehavioral Reviews, 82, 95-109.

Appel, H., Gerlach, A. L., \& Crusius, J. (2016). The interplay between Facebook use, social comparison, envy, and depression. Current Opinion in Psychology, 9, 44-49.

Barrett, L. F., Mesquita, B., Ochsner, K. N., \& Gross, J. J. (2007). The experience of emotion. Annual Review of Psychology, 58, 373-403.

Beck, A. T., \& Haigh, E. A. (2014). Advances in cognitive theory and therapy: The generic cognitive model. Annual Review of Clinical Psychology, 10, 1-24.

Brosnan, S. F., \& de Waal, F. B. (2014). Evolution of responses to (un)fairness. Science, 346(6207), 1251776.

Cohen-Charash, Y., \& Mueller, J. S. (2007). Does perceived unfairness exacerbate or mitigate interpersonal counterproductive work behaviors related to envy? Journal of Applied Psychology, 92(3), 666.

Dryden, W. (2003). Overcoming envy (Overcoming common problems). London: Sheldon Press.

Ekman, P. (1992). Are there basic emotions? Psychological Review, 99(3), 550-553. https://doi.org/10.1037/0033-295x.99.3.550.

Ekman, P. (2003). Emotions revealed: Recognizing faces and feelings to improve communication and emotional life. Times Books/ Henry Holt and Co.

Festinger, L. (1954). A theory of social comparison processes. Human Relations, 7(2), 117-140.

Fiske, S. T. (2010). Envy up, scorn down: How comparison divides us. American Psychologist, 65(8), 698-706. https://doi. org/10.1037/0003-066X.65.8.698.

Fiske, S. T. (2011). Envy up, scorn down: How status divides us. New York: Russell Sage Foundation.

Frijda, N. H. (1988). The laws of emotion. American Psychologist, 43(5), 349-358.
Gilbert, P., \& Allen, S. (1998). The role of defeat and entrapment (arrested flight) in depression: An exploration of an evolutionary view. Psychological Medicine, 28, 585-598.

Hill, S. E., \& Buss, D. M. (2006). Envy and positional bias in the evolutionary psychology of management. Managerial and Decision Economics, 27, 131-143.

Hill, S. E., \& Buss, D. M. (2008). The evolutionary psychology of envy. In R. H. Smith (Ed.), Envy: Theory and research (pp. 60-70)., Series in affective science New York: Oxford University Press.

Hill, S. E., DelPriore, D. J., \& Vaughan, P. W. (2011). The cognitive consequences of envy: Attention, memory, and self-regulatory depletion. Journal of Personality and Social Psychology, 101(4), 653.

Izard, C. E. (2009). Emotion theory and research: Highlights, unanswered questions, and emerging issues. Annual Review of Psychology., 60, 1-25. https://doi.org/10.1146/annurev.psych.60.11070 7.163539 .

Lange, J., \& Crusius, J. (2015). Dispositional envy revisited: Unraveling the motivational dynamics of benign and malicious envy. Personality and Social Psychology Bulletin, 41(2), 284-294.

Leahy, R. L. (2015). Emotional schema therapy. New York: Guilford Publications.

Lindholm, C. (2008). Culture and envy. In R. Smith (Ed.), Envy: Theory and research. Oxford: Oxford University Press.

Lindquist, K. A., \& Barrett, L. F. (2008). Constructing emotion: The experience offear as a conceptual act. Psychological Science, 19, 898-903.

Mazur, A. (1985). A biosocial model of status in face-to-face primate groups. Social Forces, 64(2), 377-402.

Oatley, K., \& Johnson-Laird, P. N. (1987). Towards a cognitive theory of emotions. Cognition and Emotion, 1(1), 29-50.

Parrott, W. G. (1991). The emotional experiences of envy and jealousy. In P. Salovey (Ed.), The psychology of jealousy andenvy (pp. 3-30). New York: Guilford Press.

Plutchik, R. (2001). The nature of emotions. American Scientist, 89(4), 344-350.

Quintanilla, L., \& de Lopez, K. J. (2013). The niche of envy: Conceptualization, coping strategies, and the ontogenesis of envy in cultural psychology. Culture \& Psychology, 19(1), 76-94.

Sapolsky, R. M. (2004). Social status and health in humans and other animals. Annual Review of Anthropology, 33, 393-418.

Sapolsky, R. M. (2005). The influence of social hierarchy on primate health. Science, 308(5722), 648-652.

Schoeck, H. (1969). Envy: A theory of social behavior. Indianapolis: Liberty Fund.

Sell, A., Tooby, J., \& Cosmides, L. (2009). Formidability and the logic of human anger. PNAS, 106(35), 15073-15078.

Van Dijk, W. W., Ouwerkerk, J. W., Goslinga, S., Nieweg, M., \& Gallucci, M. (2006). When people fall from grace: Reconsidering the role of envy in schadenfreude. Emotion, 6(1), 156.

van de Ven, N., Zeelenberg, M., \& Pieters, R. (2012). Appraisal patterns of envy and related emotions. Motivation and Emotion, 36(2), 195-204. https://doi.org/10.1007/s11031-011-9235-8.

van de Ven, N., Zeelenberg, M., \& Pieters, R. (2009). Leveling up and down: The experiences of benign and malicious envy. Emotion, 9(3), 419-429. https://doi.org/10.1037/a0015669.

van de Ven, N., Zeelenberg, M., \& Pieters, R. (2011). Why envy outperforms admiration. Personality and Social Psychology Bulletin, 37(6), 784-795.

Publisher's Note Springer Nature remains neutral with regard to jurisdictional claims in published maps and institutional affiliations. 